\title{
Serious Games for Mobile Devices: the InTouch Project Case Study
}

\author{
Alfredo Imbellone ${ }^{1 *}$, Brunella Botte ${ }^{1}$, Carlo Maria Medaglia ${ }^{1}$ \\ ${ }^{1}$ Digital Administration and Social Innovation Center (DASIC), Link Campus University, \\ via Nomentana, 335, 00162, Rome, Italy \\ \{a.imbellone, b.botte, c.medaglia\}@unilink.it
}

\begin{abstract}
The paper presents the InTouch project and discusses design principles, implementation and evaluation of serious mobile games for the development of soft skills. 30 serious games for mobile devices were produced to be tested and evaluated during Learning Labs participated by SMEs professionals operating in different business sectors from seven European countries. The games describe situational learning cases related to 10 non routine skills, and use different types of interaction. Evaluation results are described, showing an overall positive impact deriving from the choice of the serious game approach and the use of mobile devices. When analyzing the role of different dimensions of the games, the most relevant elements influencing players' satisfaction and their will to play again were found to be the levels of fun and difficulty associated with the games, the interest, the sense of reality and the adequacy of duration of the games.
\end{abstract}

Keywords: Serious games, Mobile game-based learning, Soft skills;

\section{Introduction}

Labour market asks employees to be flexible and adaptable. Personal competencies must be continuously updated in order to keep pace with rapid changes. Programmes to enhance skills must be relevant to workers and meet market demand, being flexible enough, both in content and in how they are delivered in terms of scheduling, duration, and location. Training sessions have to be accessible beyond and outside traditional classrooms to meet workers' availability in terms of space and time, while at work, at home, or moving from home to work and vice versa.

Fortunately, advances in technology and methodology provide new educational and lifelong learning opportunities. Mobile game-based learning is widely and rapidly spreading thanks to its characteristics of mobility and portability, flexibility, accessibility, and informality [1][2]. Serious Games (SG) are regarded as a perfect environment for teaching soft skills that support selfefficacy, self-directed learning and reflection upon performance [3][4][5][6]. M-learning main advantages are considered making learning contents available anytime and anywhere and linking learning to activities in the outside world environment [7][8]. Time for learning through mobile games can vary from small casual bursts to a total immersion for hours [9][10][11].

Learning Mechanics (LM) - Game Mechanics (GM) framework (LM-GM) constitutes a model for discovering and understanding which game mechanics are better related to relevant pedagogical objectives in a serious game [12]. Serious Game Mechanics (SGMs) are the game components that translate a pedagogical practice/pattern into concrete game mechanics directly perceivable by a player's actions [13]. SGMs reflect the relationships between pedagogy, learning and entertainment/fun, joining educational and gaming agendas. LM-GM framework proposes to identify the key components that can be replicated across different serious games in order to promote an efficient analysis of SGs and support specification of new designs.

This paper illustrates the InTouch project, whose main focus was the development of serious games for smartphones and tablets to teach adult workers how promptly answer to non routine situations at work. The project aimed to develop an ad hoc mobile learning kit for adult learners based on a set of 30 games designed to be usable, to challenge players to confront them with non routine tasks involving soft skills. Games were made available to be downloaded or played via Internet. InTouch's games were designed in order to be playable at any time of the day: short, simple and with a really straightforward interface with very simple functions. At the end of the 
project, games were tested to measure players' satisfaction about different dimensions, investigating which components contribute to the effectiveness of the developed mobile gamebased learning solution.

This paper describes the steps through which the InTouch project developed the mobile serious games learning kit, and some findings about the evaluation of the serious games made with a sample of users. Section 2 deals with the approach in designing games' interface, contents, interactions and learning mechanics. Section 3 describes the methodology for choosing the soft skills to be addressed by games, and the evaluation that was made both in the formative and in the summative phase. Section 4 illustrates the results obtained for each step described in the methodology section: the list of soft skills that were taken in consideration, the results of the formative and of the summative evaluation. It seems to be of a certain interest what has been found analyzing the multivariate structure of the variables considered in the summative evaluation. For this reason, Section 5, drawing conclusion of the present study, is mainly dedicated to discuss to what extent the different components of the developed serious games contribute to engage players, and keep them playing again.

\section{The InTouch project approach}

In November 2010, a consortium of European partners, belonging to seven countries (Italy, England, Sweden, Switzerland, Austria, Lithuania, Bulgaria), started working on "Labour Market InTouch: new non-routine skills via mobile game-based learning" project, funded by Leonardo da Vinci Multilateral projects for Development of Innovation Program funded by the European Commission. InTouch aimed to define an innovative approach enabling new generations of workers to develop non routine skills according to the new exigencies of the labour market.

Following the European Commission "New Skills for New Jobs" strategy [14], an innovative mlearning kit for working adults was designed, focusing on crucial non routine skills, in order to improve self-learning through educational serious games and to provide SMEs employees with the key skills needed to answer to labour market requests and to deal with the deep changes taking place.

It was chosen to deliver the games via the two most personal and portable technologies: smartphones and tablets, even if a considerable amount of mobile games are delivered through specific game consoles. The choice of smartphones and tablets was due to their versatility that makes them suitable for educational purposes, while game consoles were considered more indicated for pure entertainment.

\subsection{User interface design}

InTouch partners decided not to simply port pc style games to mobile. Instead, all games were designed to be easy to use, and the design took into account the small display dimensions of the devices and their particular ways of interaction. The InTouch games' scenarios are simple and a simple touch, or click, is enough to interact with the game, thus enabling one-hand playing. InTouch partners were mindful to keep usage costs as low as possible: indeed it was made possible to download the games and play them offline. The games are short and simple to use: no training or any special equipment is needed. Each game presents a single type of interaction and can be played quickly. Users can easily play the games anywhere and at any time: at work or at home, or even on the way to/from work/home, at a convenient time.

\subsection{Content design}

Learning contents were mapped to game style, embedding them naturally in the game with a variety of game context and complexity, fostering novelty, surprise, and humour. To make the learners feel comfortable with the topics of the games, and to allow them to optimize the retention of the contents it was chosen to connect contents to learners' past experiences: each game situation is set in a well-known working context for any SME's employee, with characters archetypes designed on real SME's employees. Playing the games users discover the problems and their possible solutions in a real life environment. The games take place in situations and contexts that are characteristic of day-to-day activities, namely within a small company titled "InTouch". The "InTouch" company is composed by several characters that were described giving their company role (Chief, PM-Design, PM-Development, PM-Assistance, Account, Account assistant, Supplier, 
Practitioner), personal information (name, surname, age, sex, star sign, hobbies), and a short bio (see Figure 1). Games scenarios were obtained adapting situational cases found with a starting field research to the "InTouch" company and its characters.

The "InTouch" company elements that connect humor, sense and meaning are characters' dossier and stories that were shortly given at the beginning of the games and more extensively published on the "InTouch" Facebook page. Each dossier reported elements of the characters' lives, funny events from their past, additional information about their relationships, hobbies and funny photographs showing something weird about them.

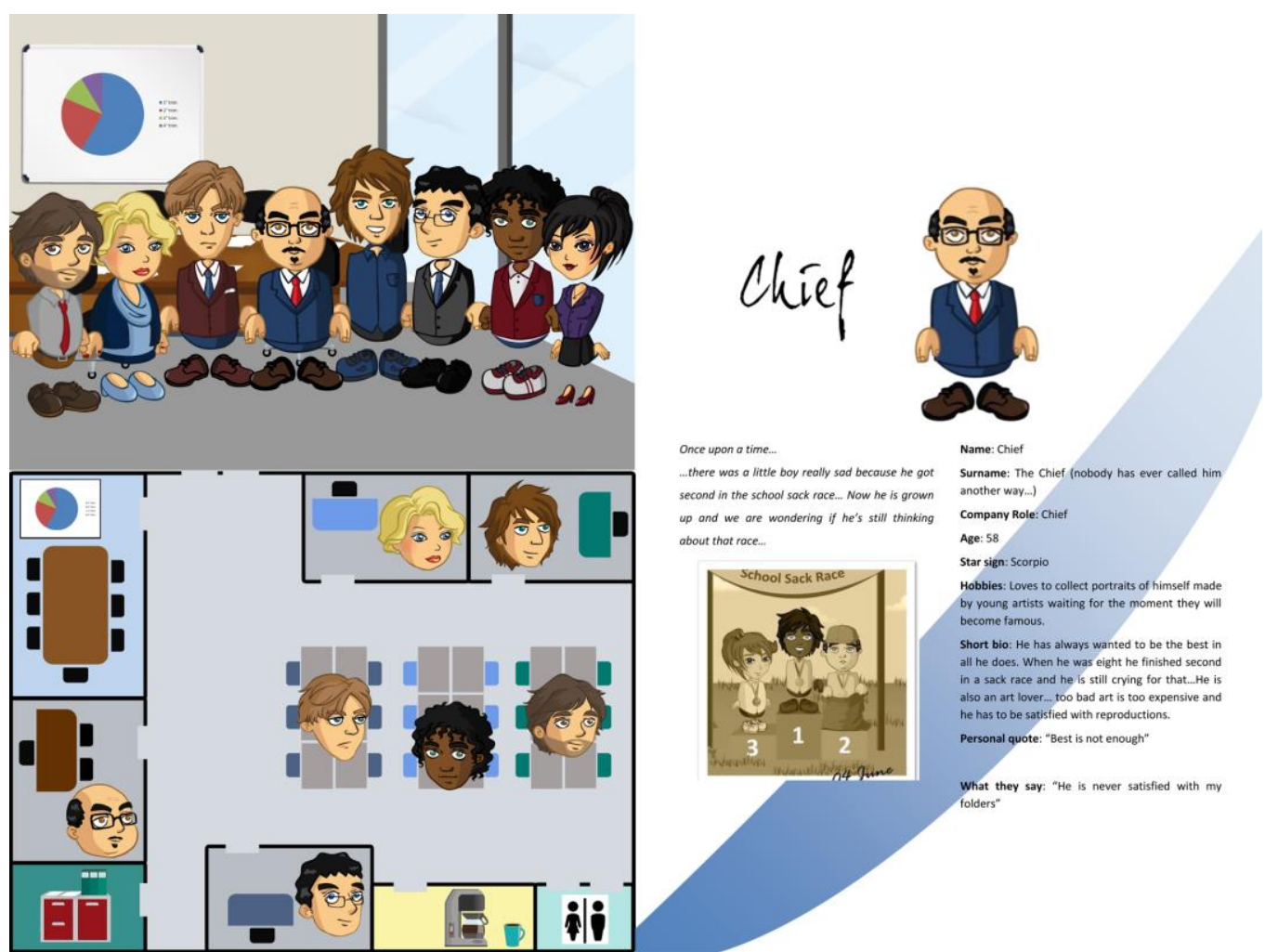

Figure 1. Screenshots of the games. Clockwise from top left: the "InTouch" company team; a single character description; an interactive map example

\subsection{Gameplay design}

One of the challenges in designing games that were simple, suitable for mobile devices, and having soft skills as topic, was to combine learning mechanics and game mechanics. Games had to be instructive, giving information and assessing players through questions. The engagement of the players had to be guaranteed in terms of motivation and challenge. Learners had to be faced with realistic actions/tasks with the scope of facilitating reflection and exploration of soft skills.

For this reason five different kinds of interaction were chosen:

- Branching stories: the user reads the story and has to take different decisions. The story develops in different ways according to the choices made by users and the final feedback and evaluation are the result of the combination of the choices.

- Interactive maps: at the beginning of the game a problem-based situation is described in the "InTouch" company. To solve the problem, the user can choose three members of the company to talk to, but he/she needs to pick the right people to get the useful information. Once the user has read the three clues he/she can choose one of the three available alternatives. Evaluation is based on the final decision and on the choice of the members of the "InTouch" company made by the player.

- Multiple choices: at the beginning of the game there is a description of a scenario and the aim of the game. The user has to help the main character with three different decisions in a limited time frame. The difficulty increases: in the first decision point only three out of the five listed options are correct, in the second one only two and in the third one only one. The final score and the feedback depend on how many correct answers the user chooses.

- Quizzes: the game begins presenting a brief introduction of the main topic, than the player has to try to correctly answer three related questions. The player gets immediate feedback 
on the answer to each question and a summary at the end of game. The key objective is to gain points for fast and correct answers. Evaluation is based on a combination of the number of correct answers with the time taken to answer.

- Simulations: during the game the user has to achieve a goal, which foresees three different tasks. He/she has to make sure to do the right tasks in the right order and then he/she has to answer to a question focused on the selected task. The score is determined from the number of correct answers and from the order the user chose to prioritize the tasks.

The choice of the above mentioned gameplay was made according to the LM-GM framework, as reported in Table 1, matching elements of Learning Mechanics (actions and elements that can foster learning), and Game Mechanics, typical of the gaming activity.

Table 1. LM-GM model for InTouch serious games

\begin{tabular}{lrr}
\hline Learning Mechanics & Game Mechanics \\
\hline Instructional & Branching Story & Goods/information \\
Motivation & & Role play - Realism \\
Action/Task & Strategy/Planning \\
Reflect/Discuss & Feedback \\
Instructional & & \\
Motivation & & Goods/information \\
Explore & & Role play \\
Action/Task & Multiple Choice & Selecting/Collecting \\
Reflect/Discuss & & Questions \& Answers \\
Instructional & Feedback \\
Competition & & Question \& Answers \\
Motivation & & Levels - Time pressure \\
Action/Task & Reward/Penalties \\
Reflect/Discuss & & Question \& Answers \\
& & Feedback \\
Instructional & & Question \& Answers \\
Competition & Levels \\
Motivation & Quiz & Reward/Penalties \\
Action/Task & & Question \& Answers \\
Reflect/Discuss & & Feedback \\
Instructional & & Simulate/Response \\
Competition & Strategy/Planning \\
Motivation & & Rewards/Penalties \\
Action/Task & & Feedback \\
Reflect/Discuss & &
\end{tabular}

\subsection{Workflow design}

Once that interface, content, and interactions were designed, as described above, the workflow process was standardized in order to reduce marginal costs in the development of the serious games. A graphics library with characters and settings of the "InTouch" company was created to be used across different games. All games were designed according to the same scheme made of an opening scenario where the context of the game referred to the "InTouch" company is described (frame 1), after that a problem-based situation is presented with the aim of the game (frame 2), three interactive frames constitute the core of the game where players are asked to choose among different options (frames 3, 4, 5), the last frame is dedicated to the conclusion of the game, showing the score and giving feedback to the players. It was thus possible to standardize both the process of storyboarding and the multimedia development of the games, using templates whose only differences were limited to the central frames, according to the type of interaction the game was based on (i.e. branching story, interactive map, multiple choice, quiz, or simulation). Furthermore, for the translation of the games, spreadsheets were prepared and distributed among the partners to collect different languages versions. All these elements guaranteed a sufficient scalability and the automation of the design and development process, reducing significantly the marginal costs for the final production of 30 serious games, each one translated in seven different languages. 


\section{Methodology}

\subsection{Field research}

A field research was conducted in the first phase of the project to define the crucial key competences for non routine tasks, and identify a collection of non routine situational cases for each competence to be used within the games. Non routine skills have been defined through a questionnaire made of a list of non routine tasks, using exploratory factor analysis and validation. Personal in-depth interviews were then conducted with employees and managers of European business service SMEs from the seven different countries of the partners. During interviews, each respondent was asked to evaluate skills that had emerged from the questionnaire results and to provide related cases to associate situational cases to each skill. Each situational case was defined giving a description of the workplace situation/problem, of the objective to be reached with the use of the addressed skill, and of a list of solutions (at least 5) to face the described situation/problem. From an initial list of 50 situational cases revealed by interviews ( 5 for each skill), a reduced list of 30 situational cases ( 3 for each skill), obtained clustering and combining the previous ones, was finally stated as starting point for developing games scenarios and objectives.

\subsection{Formative evaluation}

In the formative phase, five game prototypes were tested, one for each type of gameplay (i.e. branching story, interactive map, multiple choice, quiz, and simulation), and having a specific soft skill as topic. Formative evaluation was conducted with a group of 20 participants, formed by SMEs employees who accepted an invitation and people belonging to the partners' staff. Participants were asked to play the games, and then to fill in a grading grid about the game design, the training content, and other aspects of the games.

The results of the formative evaluation were used to guide the further development of games, modifying those aspects that reported usability problems, improving those dimensions of the games that resulted to be less appreciated, and endorsing those games that were based on the interactions which showed to be most successful. Following these indications the 5 prototypes were finalized and 25 more games were developed, thus obtaining the final kit of 30 serious games.

\subsection{Summative evaluation}

After the development of 30 serious games, seven Learning Labs, one for each country of the partners, were held to evaluate the usefulness of the InTouch m-learning kit. Every Learning Lab made use of the same evaluation instruments and methodology.

Each Learning Lab was articulated in three phases: (1) presentation, the InTouch m-learning approach, the "Be competitive" handbook, and the 30 learning games were presented; (2) testing, participants had the opportunity to play the InTouch m-learning games and then to answer a questionnaire; (3) discussion, a final debrief in the form of Focus group aimed to collect additional information/feedback/suggestions about the use of the InTouch m-learning kit. The data of the questionnaire collected during the Learning Labs are analyzed in the present study to find the correlation between variables and to what degree they contribute to determine the will to play again.

\section{Results}

\subsection{Field research results}

The questionnaire to identify the most relevant non routine skills collected 62 respondents and was formed by 51 items describing tasks/behaviors related to skill management. Respondents were asked to express their opinion about the degree of importance for each item on a 10-point Likert scale. At first all questions were factorized by principal components method, while applying factors axis rotation according to the highest dispersion (varimax rotation). When the structure of theoretically meaningful indicators was found, obtained single factors (10 skills) were additionally tested by applying alpha factor analysis method. Their inherent consistency coefficients were found to be high enough (Cronbach's Alpha index ranging from 0.6 to 0.8). 
The 10 factors resulting from the factorial analysis were interpreted according to items content and labeled as: communication; planning; conflict management; openness to change; decision making; teamwork; flexibility; strategic thinking; initiative; learning and improvement.

Table 2 and Table 3 summarize the results of the factorial analysis and questionnaire validation. Table 2 reports items content, and for each item the loading (L) on the corresponding competence factor after varimax rotation and the item-total-correlation $(\mathrm{i} / \mathrm{tt})$. Loading values were found to be above 0.50 for all items, while the item-total-correlation values were all above 0.20 . For these reasons no item was removed from the questionnaire.

Table 1. Field research questionnaire: factor analysis and validation

\begin{tabular}{|c|c|c|c|}
\hline Skill & Behaviour /Item & $\mathbf{L}$ & $\mathbf{i} / \mathbf{t t}$ \\
\hline \multirow[t]{4}{*}{ Initiative } & Actively seeks new activities and work challenges & .664 & .335 \\
\hline & Actively seeks and identifies opportunities to achieve goals & .653 & .335 \\
\hline & Actively seeks out new information/precedents & .601 & .266 \\
\hline & Pursues work with energy and determination & .591 & .258 \\
\hline \multirow{4}{*}{$\begin{array}{l}\text { Strategic } \\
\text { thinking }\end{array}$} & Possesses a clear vision for the future & .836 & .665 \\
\hline & Clearly defines key objectives & .754 & .547 \\
\hline & Considers the company in relation to its external environment & .746 & .545 \\
\hline & $\begin{array}{l}\text { Identifies opportunities which can increase the organization's } \\
\text { competitiveness }\end{array}$ & .730 & .521 \\
\hline \multirow[t]{4}{*}{$\begin{array}{l}\text { Openness } \\
\text { to change }\end{array}$} & $\begin{array}{l}\text { Realizes the need for change, and the possibility of implementing the } \\
\text { change }\end{array}$ & .810 & .537 \\
\hline & Initiates and implements change & .745 & .454 \\
\hline & Adapts to the changing environment both by behavior and thinking & .612 & .356 \\
\hline & Supports new approaches, initiatives, methods, and technologies & .604 & .339 \\
\hline \multirow[t]{4}{*}{ Team work } & Fosters commitment and team spirit & .848 & .633 \\
\hline & Encourages and facilitates cooperation in team working & .806 & .565 \\
\hline & Works with others to achieve goals & .748 & .489 \\
\hline & Integrates different opinions of team members & .509 & .306 \\
\hline \multirow{4}{*}{$\begin{array}{l}\text { Learning, } \\
\text { improvement }\end{array}$} & Continually improves personal behaviours & .828 & .646 \\
\hline & Continually improves professional knowledge and skills & .748 & .532 \\
\hline & Strives to learn more than required by each situation & .739 & .537 \\
\hline & Learns from own experience & .726 & .507 \\
\hline \multirow[t]{4}{*}{$\begin{array}{l}\text { Decision } \\
\text { making }\end{array}$} & $\begin{array}{l}\text { Evaluates the consequences and risks, expected benefit and cost of } \\
\text { decisions taken }\end{array}$ & .825 & .586 \\
\hline & Evaluates strategic impact of decisions taken & .790 & .558 \\
\hline & Makes good decisions in complex situations & .747 & .481 \\
\hline & Presents logical, reasoned, constructive critical comments and arguments & .578 & .339 \\
\hline \multirow[t]{3}{*}{ Planning } & Anticipates progress of actions and resources required & .796 & .471 \\
\hline & Defines priorities & .729 & .398 \\
\hline & Distributes and redistributes tasks and resources & .724 & .398 \\
\hline \multirow{4}{*}{$\begin{array}{l}\text { Conflict } \\
\text { management }\end{array}$} & Acts as a mediator in conflict situation & .838 & .657 \\
\hline & Resolves conflicts among people & .765 & .564 \\
\hline & Is fair and objective in conflict situations & .725 & .513 \\
\hline & Handles stress in conflict situations & .700 & .487 \\
\hline \multirow[t]{6}{*}{ Communication } & Is open to feedback from others without prejudice & .796 & .635 \\
\hline & Respects the attitudes and opinion of others & .795 & .649 \\
\hline & Provides feedback to others & .762 & .604 \\
\hline & Can discuss different topics in an objective way & .647 & .486 \\
\hline & Is tolerant of different customs and cultures & .602 & .437 \\
\hline & Presses own reflections and ideas clearly & .540 & .380 \\
\hline \multirow{3}{*}{ Flexibility } & Takes into account the attitudes and views of others & .908 & .752 \\
\hline & Understand and adopt the position of others & .832 & .616 \\
\hline & Adapts to changing demands and conditions & .786 & .561 \\
\hline
\end{tabular}

$\mathrm{n}=62 ; \mathrm{L}=$ Loading after varimax rotation; $\mathrm{i} / \mathrm{tt}=$ Item-total-correlation

Table 3 summarizes the results about questionnaire consistency and reliability, reporting descriptive statistics for each factor (Mean and Standard deviation), together with Cumulative percentages of explained variances (\%) by each factor's items, Cronbach's Alpha for each factor, and the Kaiser-Meyer-Olkin Measure of Sampling Adequacy (KMO). Cronbach's Index threshold for acceptance of internal consistency was taken at 0.5, Kaiser-Meyer-Olkin indication of sampling adequacy was considered above 0.5 . Both conditions were satisfied by the considered sample. All the Cumulative percentages of explained variances resulted to be above $50 \%$. 
Table 2. Field research questionnaire consistency and reliability

\begin{tabular}{llllll}
\hline Skill & M & SD & \% & $\boldsymbol{\alpha}$ & KMO \\
\hline Communication & 3.399 & .459 & 58.67 & .783 & .658 \\
Planning & 3.392 & .516 & 56.30 & .611 & .629 \\
Conflict management & 3.389 & .524 & 57.58 & .752 & .746 \\
Openness to change & 3.383 & .488 & 58.75 & .643 & .624 \\
Decision making & 3.360 & .477 & 55.77 & .675 & .741 \\
Team work & 3.340 & .508 & 54.70 & .711 & .719 \\
Flexibility & 3.333 & .624 & 51.11 & .795 & .639 \\
Strategic thinking & 3.325 & .599 & 58.94 & .767 & .730 \\
Initiative & 3.317 & .416 & 59.45 & .607 & .619 \\
Learning, improvement & 3.275 & .610 & 57.94 & .757 & .744 \\
\hline
\end{tabular}

$\mathrm{M}=$ Mean, $\mathrm{SD}=$ Standard Deviation, $\%=$ Cumulative percentages of explained variance, $\alpha=$ Cronbach's Index, KMO = Kaiser-Meyer-Olkin Index

\subsection{Formative evaluation results}

Formative evaluation was conducted in the second phase of the project, with 5 game prototypes until then developed (one for each kind of game interaction) and two small groups of participants (10 people for each group). An articulated grading grid was proposed to participants, distinguishing among different types of interaction and asking them to express on a 10 point Likert scale their opinion about the game design, duration, interest of the goal and reality of the game scenarios, fun, quality of the instructions, level of difficulty, learning/educative content, quality of the feedback, and the will to play again with the game. Table 4 summarizes the results of the grading grid, reporting the averaged scores obtained for each type of game interaction.

Table 3. Grading grids results for the formative evaluation ( $n=20$ participants)

\begin{tabular}{lccccc}
\hline Type of game & $\begin{array}{c}\text { Branching } \\
\text { story }\end{array}$ & $\begin{array}{c}\text { Quiz } \\
\text { Interactive } \\
\text { map }\end{array}$ & Simulation & $\begin{array}{c}\text { Multiple } \\
\text { choice }\end{array}$ \\
\hline Duration & 6.5 & 4.2 & 7.3 & 6.8 & 6.7 \\
Design & 8.2 & 6.7 & 5.3 & 5.5 & 4.5 \\
Fun & 4.8 & 3.8 & 4.7 & 5.5 & 5.5 \\
Quality of the instructions & 8.0 & 6.8 & 8.3 & 8.2 & 7.0 \\
Right level of difficulty & 8.2 & 4.5 & 9.1 & 6.3 & 7.3 \\
Interest of the goal & 6.8 & 3.9 & 5.7 & 5.9 & 5.5 \\
Learning/educative content & 5.5 & 4.2 & 7.1 & 6.5 & 6.2 \\
Quality of the feedback & 5.8 & 4.8 & 5.9 & 6.7 & 6.0 \\
Reality of the situation & 7.7 & 5.1 & 6.1 & 6.9 & 5.8 \\
Will to play again & 6.4 & 1.8 & 4.5 & 4.6 & 5.5 \\
\hline
\end{tabular}

Useful indications for the further development of the games emerged from the formative evaluation. The most critical type of gameplay was found to be the quiz, perceived as too easy and substantially not instructive, so that most people were not motivated to play it again. On the contrary, the best results were those obtained by branching stories, simulations and interactive maps that were perceived as engaging, challenging and motivating. More fun content was suggested as an improving factor to be developed for every kind of interaction.

\subsection{The InTouch m-learning kit}

As a result of the aforementioned design elements, combined with the results of the field research and the formative evaluation, a kit of 30 games was finally developed. Three games, each one consisting of a single interaction type (i.e. branching story, quiz, interactive map, simulation, or multiple choice), were assigned to each non routine skill (i.e. communication, planning, conflict management, openness to change, decision making, teamwork, flexibility, strategic thinking, initiative, leaning and improvement), according to the matrix reported in Table 5, where each $\mathrm{X}$ represents a game. The games that were based on branching story and interactive map interactions were developed for every skill because of their positive formative evaluation, thus obtaining 20 games. Ten more games were based on the other kinds of interaction (i.e. quiz, simulation, and multiple choice) and equally distributed among the considered skills. 
Table 4. Games - Skills Matrix

\begin{tabular}{|c|c|c|c|c|c|}
\hline \multirow[b]{2}{*}{ Skill } & \multicolumn{5}{|c|}{ Game (for type of interaction) } \\
\hline & $\begin{array}{c}\text { Branching } \\
\text { story }\end{array}$ & Quiz & $\begin{array}{c}\text { Interactive } \\
\text { map }\end{array}$ & Simulation & $\begin{array}{c}\text { Multiple } \\
\text { choice }\end{array}$ \\
\hline Communication & $\mathrm{X}$ & & $\mathrm{X}$ & $\mathrm{X}$ & \\
\hline Planning & $\mathrm{X}$ & & $X$ & $X$ & \\
\hline Conflict management & $\mathrm{X}$ & & $\mathrm{X}$ & & $X$ \\
\hline Openness to change & $\mathrm{X}$ & $\mathrm{X}$ & $\mathrm{X}$ & & \\
\hline Decision making & $\mathrm{X}$ & & $X$ & $X$ & \\
\hline Teamwork & $X$ & & $X$ & & $\mathrm{X}$ \\
\hline Flexibility & $\mathrm{X}$ & $\mathrm{X}$ & $X$ & & \\
\hline Strategic thinking & $\mathrm{X}$ & & $X$ & $\mathrm{X}$ & \\
\hline Initiative & $\mathrm{X}$ & & $X$ & & $X$ \\
\hline Learning, improvement & $\mathrm{X}$ & $\mathrm{X}$ & $\mathrm{X}$ & & \\
\hline
\end{tabular}

\subsection{Summative evaluation results}

Summative evaluation was conducted with the kit of 30 mobile serious games that were developed in the last phase of the project. Evaluation sessions were held during seven different Learning Labs that involved in all 54 person (28 managers and 26 employees) of SMEs operating in different business sectors (ICT, business support, education/training, etc.). There were 30 men and 24 women. Age distribution was: $20-35$ years (16 people); $36-50$ years (23 people); 51-65 years (15 people). The questionnaire proposed during the Learning Labs was formed using the same items already present in the formative grading grid. Participants were asked to play at least one game for each type of interaction, and to answer the questionnaire after the completion of each game. At the end of the Learning Labs participants were asked to write down three advantages and three disadvantages about their experience with the games. These lists of advantages and disadvantages were finally discussed in a Focus group.

On the whole, 298 game sessions were played during the Learning Labs, covering all the 30 developed serious games. Table 6 shows the grading grids' results, where the averages, based on the kind of interaction of each game, are considered. When compared to the formative test, a general improvement can be seen, except for the level of difficulty that was less appreciated, while the fun aspect of the games significantly increased.

Table 5. Grading grids results for the summative evaluation ( $\mathrm{n}=54$ participants) and their difference with the results of the formative evaluation (within parentheses)

\begin{tabular}{|c|c|c|c|c|c|}
\hline \multirow[t]{2}{*}{ Dimension } & \multicolumn{5}{|c|}{ Type of game } \\
\hline & $\begin{array}{l}\text { Branching } \\
\text { story }\end{array}$ & Quiz & $\begin{array}{c}\text { Interactive } \\
\text { map }\end{array}$ & Simulation & $\begin{array}{c}\text { Multiple } \\
\text { choice }\end{array}$ \\
\hline \multirow[t]{2}{*}{ Duration } & 6.5 & 4.8 & 7.8 & 7.0 & 7.0 \\
\hline & $(=)$ & $(+0.6)$ & $(+0.5)$ & $(+0.2)$ & $(+0.3)$ \\
\hline \multirow{2}{*}{ Design } & 8.5 & 6.8 & 6.3 & 6.3 & 5.5 \\
\hline & $(+0.3)$ & $(+0.1)$ & $(+1.0)$ & $(+0.8)$ & $(+1.0)$ \\
\hline \multirow[t]{2}{*}{ Fun } & 7.8 & 5.6 & 7.3 & 6.8 & 6.5 \\
\hline & $(+3.0)$ & $(+1.8)$ & $(+2.6)$ & $(+1.3)$ & $(+1.0)$ \\
\hline \multirow[t]{2}{*}{ Quality of the instructions } & 8.0 & 7.9 & 8.4 & 8.2 & 7.8 \\
\hline & $(=)$ & $(+1.1)$ & $(+0.1)$ & $(=)$ & $(+0.8)$ \\
\hline \multirow[t]{2}{*}{ Right level of difficulty } & 8.0 & 4.2 & 8.7 & 6.3 & 6.1 \\
\hline & $(-0.2)$ & $(-0.3)$ & $(-0.4)$ & $(=)$ & $(-1.2)$ \\
\hline \multirow[t]{2}{*}{ Interest of the goal } & 6.8 & 4.5 & 6.3 & 6.6 & 6.1 \\
\hline & $(=)$ & $(+0.6)$ & $(+0.6)$ & $(+0.7)$ & $(+0.6)$ \\
\hline \multirow[t]{2}{*}{ Learning/educative content } & 5.6 & 5.2 & 7.2 & 7.0 & 6.8 \\
\hline & $(+0.1)$ & $(+1.0)$ & $(+0.1)$ & $(+0.5)$ & $(+0.6)$ \\
\hline \multirow[t]{2}{*}{ Quality of the feedback } & 6.0 & 5.1 & 6.1 & 6.9 & 6.3 \\
\hline & $(+0.2)$ & $(+0.3)$ & $(+0.2)$ & $(+0.2)$ & $(+0.3)$ \\
\hline \multirow[t]{2}{*}{ Reality of the situation } & 7.7 & 6.0 & 7.1 & 6.9 & 6.4 \\
\hline & $(=)$ & $(+0.9)$ & $(+1.0)$ & $(=)$ & $(+0.6)$ \\
\hline \multirow[t]{2}{*}{ Will to play again } & 7.4 & 2.9 & 5.5 & 6.6 & 6.3 \\
\hline & $(+1.0)$ & $(+1.1)$ & $(+1.0)$ & $(+2.0)$ & $(+0.8)$ \\
\hline
\end{tabular}

As a further analysis the correlation among the ten variables measured by the questionnaire was studied. Single values were considered for each variable without distinguishing among different 
types of game interaction (for each variable the value was given by the weighted average among the five different types of game interaction). Correlation matrix is reported in Table 7.

Table 6. Correlation matrix (sub-diagonal coefficients)

\begin{tabular}{|c|c|c|c|c|c|c|c|c|c|}
\hline Variable & Play again & Dur. & Design & Fun & Instr. & Diff. & Goal & Learn & Feed \\
\hline Duration & $.78^{*}$ & & & & & & & & \\
\hline Design & $.76^{*}$ & $.80 *$ & & & & & & & \\
\hline Fun & $.89 *$ & $.93 *$ & $.79 *$ & & & & & & \\
\hline Instructions & $.64 *$ & $.79^{*}$ & $.80^{*}$ & $.66^{*}$ & & & & & \\
\hline Difficulty & $.84 *$ & $.88^{*}$ & $.92^{*}$ & $.91 *$ & $.79 *$ & & & & \\
\hline Goal & $.60 *$ & .26 & $.33 *$ & $.35^{*}$ & .26 & $.32 *$ & & & \\
\hline Learning & .17 & $.68^{*}$ & .26 & $.50 *$ & $.43 *$ & $.34 *$ & -.06 & & \\
\hline Feedbacks & $.52 *$ & $.62 *$ & $.70 *$ & $.60 *$ & $.40^{*}$ & $.69 *$ & $.46^{*}$ & $.31 *$ & \\
\hline Reality & .21 & -.05 & $.30 *$ & -.12 & $.35^{*}$ & .09 & .19 & $-.47 *$ & .01 \\
\hline
\end{tabular}

Multiple linear regression was finally conducted considering the will to play again as the dependent variable, and calculating the beta coefficients for the other nine variables taken as predictors. Results are shown in Table 8. The omnibus F-test was done to examine model fit and reject the null hypothesis implying that the linear model is not significantly suitable to the data. It was found an R-squared value of 0.992 (and Adjusted R-squared $=0.991$ ) and an observed value of $F=606.2$, well above the value of $F(0.01,9,44)=2.84$. The null hypothesis could thus be rejected with a level of significance above $99 \%$.

Table 7. Beta coefficients of Multiple regression (Dependent variable $=$ Will to play again)

\begin{tabular}{lccc}
\hline Predictors & $\boldsymbol{\beta}$ & t-value & Level of significance \\
\hline Duration & .30 & 3.202 & $99.87 \%$ \\
Design & -.16 & -3.539 & $99.95 \%$ \\
Fun & .70 & 7.616 & $100.00 \%$ \\
Instructions & -.28 & -4.074 & $99.99 \%$ \\
Difficulty & .38 & 3.459 & $99.94 \%$ \\
Goal & .33 & 13.219 & $100.00 \%$ \\
Learning & -.11 & -2.016 & $97.50 \%$ \\
Feedback & -.24 & -5.814 & $100.00 \%$ \\
Reality & .31 & 8.717 & $100.00 \%$ \\
\hline
\end{tabular}

The most relevant positive predictors of the will to play again resulted to be the level of fun $(\beta=$ .70), followed by the right level of difficulty $(\beta=.38)$, the interest of the goal $(\beta=.33)$, the degree of reality of the games $(\beta=.31)$, and the adequacy of the duration of the games $(\beta=.30)$. The relation between the learning/educative content and the will to play again was found to be not significant, while negative beta coefficients emerged in the prediction of the will to play again by the design elements $(\beta=-.16)$, the quality of the feedback $(\beta=-.24)$ and the quality of the instructions $(\beta=-.28)$.

\section{Conclusion}

Statistical results emerging from the considered sample showed that the most attractive element in the proposed serious games kit resulted to be the level of fun. That is quite an obvious consequence of having chosen the playful approach intrinsic in every kind of game. Nonetheless, it must also be considered a confirmation for the efficacy of the ludic component of our serious games. More interesting are the results showing that an important role is represented by the right level of difficulty, the interest of the goal, and the degree of reality of the games. These elements are fundamental to define the serious nature of the proposed games, and confirm the right choices adopted for the games design. In particular, the results confirm that, if the challenges of a game are adequately positioned, players will be motivated to continue to play. As previously stated, and confirmed by results, the interest of the goal is a motivating factor as well; while the significant role played by the choice of realistic game scenarios seems to confirm the importance of the narrative approach that was adopted.

The significant correlation between the duration of the games and their appreciation by players can be interpreted as particularly important in the field of mobile games. As previously mentioned, in 
fact, it was chosen to create short games that could be played in a short time, and this seemed to work well with the analyzed games kit.

No significant relationship was found between the learning/educative content of the games and the will to play them again. At first sight this could appear disappointing for a set of serious games that were specifically addressed to teach something about non routine skills. However this result can be interpreted considering that the developed games were not instructive in the traditional sense of transmitting educative contents. The proposed games were rather a way to practice soft skills in a playful way, learning by doing when faced to problematic scenarios like the ones proposed by the games. In this sense the learning/educative content can be perceived as "transparent" by the players, thus explaining the lack of correlation with the will to play again.

Furthermore, feedbacks and additional instruction are negatively linked to the will to play again. This result can be interpreted considering that in the case of very short duration mobile games, like the ones we are dealing with, both feedbacks and instructions can be perceived as boring, time wasting and useless. As an emerging indication, particular attention must be paid when designing these elements to avoid such a perception by players.

Although the LM-GM framework was taken into account when designing the interactions, no particular analysis was conducted in order to match interaction styles and soft skills. The only trivial criterion was endorsing the most appreciated interactions according to the formative evaluation results. Among the limits of the InTouch solution it must also be mentioned that a deeper and more systematic evaluation, supported by quantitative data and based on a more significant sample of users, should be conducted for evaluating learning experience and integration within existing educational and organizational contexts [15]. Furthermore it would have been scientifically more rigorous to validate the grading grid used for the evaluation, or adopting an already validated one. On the contrary, the adopted grading grid was self-developed, and consisted of only one item for each dimension.

These limits of the project will be hopefully soon addressed; in fact European Commission approved the InTouch-ICT Transfer of Innovation project (2013-2015). The InTouch-ICT Project will transfer InTouch project results to suit the learning needs of business professionals of ICT SMEs in Turkey. The transfer will be made by adapting the existing m-learning kit to the new requirement of Turkish ICT SMEs and taking advantages of the new opportunities offered by the evolution occurred during the last years in the field of mobile game-based learning.

\section{Acknowledgments}

The success of the InTouch Project was due to the support and commitment of all partners: Centre for Flexible Learning - CFL, municipality of Soderhamn (Sweden); Faculty of Economics and Management, Kaunas University of Technology (Lithuania); Exemplas Holdings Limited (United Kingdom); Centro per le Applicazioni della Televisione e delle Tecniche di Istruzione a Distanza CATTID, University of Rome "La Sapienza" (Italy); CIBC Artois Ternois (France); Evolaris next level GmbH (Austria); Centro Italiano per l'Apprendimento Permanente - CIAPE (Italy); Bulgarian Development Agency (Bulgaria); The Swiss Federation for Adult Learning - SVEB (Swiss).

\section{References}

[1] Campanella, P., "Mobile Learning: New forms of education". 10th IEEE International Conference on Emerging eLeaming Technologies and Applications, Stara Lesna, The High Tatras, Slovakia, November 8-9, 2012.

[2] Sharples, M., "Mobile learning: research, practice and challenges". Distance Education in China, 3(5), 5-11, 2013.

[3] De Freitas, S., \& Routledge, H., "Designing leadership and soft skills in educational games: The e-leadership and soft skills educational games design model (ELESS)". British Journal of Educational Technology, 44(6), 951-968, 2013. http://dx.doi.org/10.1111/bjet.12034

[4] De Freitas, S., \& Liarokapis, F., "Serious games: a new paradigm for education?". In Ma, M. et al. (Eds.), Serious games and edutainment applications, London: Springer, 2011. http://dx.doi.org/10.1007/978-1-4471-2161-9_2

[5] Prensky, M., "Digital Game-Based Learning". New York and London: McGraw-Hill, 2001.

[6] Aldrich, C., "The Complete Guide to Simulations and Serious Games: How the Most Valuable Content Will Be Created in the Age Beyond Gutenberg to Google". Pfeiffer \& Company, 2009. 
[7] Traxler, J., "Distance education and mobile learning: Catching up, taking stock". Distance Education, 31(2), 129-138, 2010. http://dx.doi.org/10.1080/01587919.2010.503362

[8] Sharples, M., Corlett, D., \& Westmancott, O., "The design and implementation of a mobile learning resource". Personal and Ubiquitous Computing, 6, 220-234, 2002. http://dx.doi.org/10.1007/s007790200021

[9] Froschauer, J., Zweng, J., Merkl, D., Arends, M., Goldfarb, D., \& Weingartner, M., "ARTournament: A Mobile Casual Game to Explore Art History". 12th IEEE International Conference on Advanced Learning Technologies, Rome, Italy, July 4-6, 2012.

[10] Csíkszentmihályi, M., "Flow: The Psychology of Optimal Experience". NewYork: Harper and Row, 1990.

[11] Lazzaro, N., "Why We Play Games: Four Keys to More Emotion Without Story". XEODesign, 2004.

[12] Arnab, S., Lim, T., Carvalho, M. B., Bellotti, F., de Freitas, S., Louchart, S., Suttie, N., Berta, R., \& De Gloria, A., "Mapping learning and game mechanics for serious games analysis". British Journal of Educational Technology, 2014. http://dx.doi.org/10.1111/bjet.12113

[13] Huynh-Kim-Bang, B., Wisdom, J., \& Labat, J.M., "Design patterns for serious games". International Journal of Technology Enhanced Learning, 3(6), 2011.

[14] New Skills for New Jobs http://ec.europa.eu/social/main.jsp?catId=822 (retrieved on 2014/11/24)

[15] Vavoula, G., \& Sharples, M., "Meeting the Challenges in Evaluating Mobile Learning: a 3level Evaluation Framework". International Journal of Mobile and Blended Learning, 1(2), 5475, 2009. http://dx.doi.org/10.4018/jmbl.2009040104 